EPiC Series in Engineering
Volume 3, 2018, Pages 2170-2177
HIC 2018. 13th International
Conference on Hydroinformatics

\title{
Generation of daily synthetic series of inflow volume to the Las Cruces Dam, Nay., Mexico, using the Svanidze method
}

\author{
Velázquez, M. I.1a , Arganis, J. M.1 ${ }^{\text {a }} 1^{\text {b }}$, Domínguez, M. R. 1ª, Mendoza, \\ R. R. $1^{\mathrm{a}}$ y Carrizosa E.E. $1^{\mathrm{a}}$ \\ ${ }^{1}$ a Instituto de Ingeniería, b Facultad de Ingeniería. Universidad Nacional Autónoma de México \\ (UNAM). Circuito Escolar s/n, Ciudad Universitaria. Ciudad de México,04510 México. \\ Corresponding author: MArganisJeiingen.unam.mx
}

\begin{abstract}
The generation of synthetic series is important for simulations of the behavior in the long term of a reservoir or systems of them. The Svanidze method is easy to use to generate periodic time series for a selected period of time (monthly, fortnightly, weekly). Compared with other methods (eg PAR, PARMA) this method does not require a normal distribution assumption for the series. In this work the Svanidze method was applied to obtain synthetic series of the daily inflow volume to the Las Cruces hydroelectric project, located in the state of Nayarit, Mexico; with this method we achieve the objective of reproducing the behavior of the historical series at least in its first moment (the mean). In addition, similar correlation coefficient are observed from one day to the next with respect to what happened historically.
\end{abstract}

Keywords: Correlation coefficient; daily inflow volume; Las Cruces Dam, Nay.; Svanidze method; Synthetic series

\section{Introduction}

The proper operation of a reservoir is analyzed knowing its levels or elevations. There are methods and probabilistic functions that help us to give an idea of how a hydrological regime will behave and with this being able to make projections of what will happen more accurately. However it is not possible to predict with certainty which event may occur, which may damage or render the works unworkable. The simulation of reservoir operating rules with the aid of records of runoff volumes longer than the historically observed ones is useful to investigate the behavior of a dam in the long term (M. L. Arganis J., 2008) (M., 2017). 
In this work, the Svanidze Method (Domínguez M. R., 2001) was applied to obtain synthetic records of daily inflow volumes for the Cruces, Nayarit hydroelectric project, which preserved the statistical behavior of the original series. Simulations were then made using these records with the operating rule proposed by the operator (Comisión Federal de Electricidad (CFE)).

\section{Methodology}

\subsection{Svanidze method}

The Svanidze method consists of a double random procedure, that is, we first obtain daily synthetic fractions that are percentages of the annual totals of random years, then we generate randomly annual volumes with the probabilistic function that best adjusts to the historical data, to finally create synthetic data by multiplying the synthetic fractions of random years by the annual volumes generated obtaining daily volumes. The method can be applied to weekly, biweekly, monthly or daily data depending on what is required and one of the most appreciable advantages is that the data may not be normal (Domínguez M. R., 2001). In this study 10 synthetic daily series of 100 years each were generated.

\subsection{Study Site and input data}

"Las Cruces" hydroelectric project is located on the San Pedro 1 Mezquital River, $10 \mathrm{~km}$ from San Pedro Ixtatán, Nayarit (Figure 1). The area of the San Pedro River basin is approximately $29,546 \mathrm{~km}^{2}$. The data used were provided by the CFE and corroborated by the Instituto de Ingeniería, UNAM (R. Domínguez M., 2016); it was counted with 68 years of record of daily inflow volumes, in $\mathrm{hm}^{3}$, to the project reservoir.The CFE proposed a policy whose purpose is to preserve as much as possible the natural regime of the channel downstream of the reservoir, to preserve the flora and fauna of mangroves near the site. 


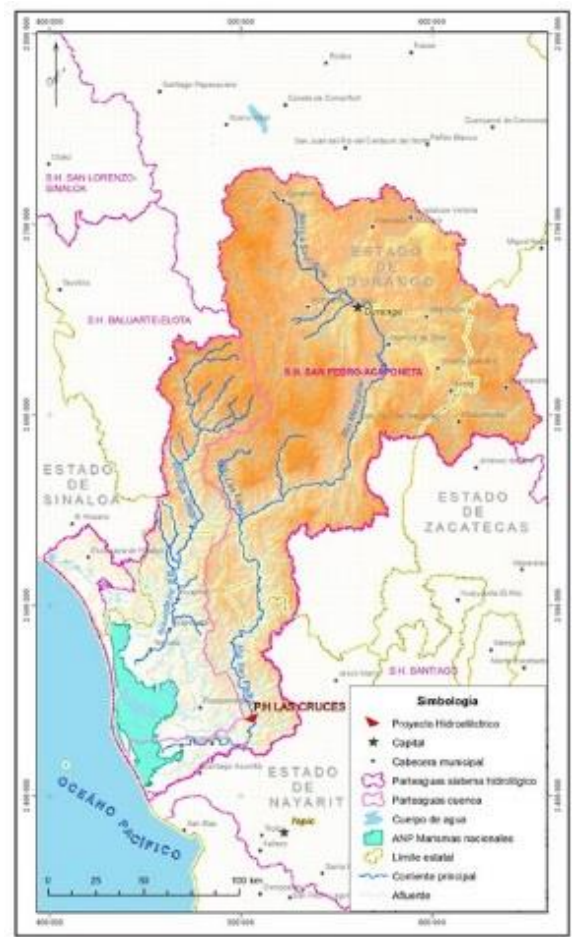

Figure 1: Las Cruces hydroelectric proyect, Nay., México (Source: CFE)

\section{Application and results}

When applying the Svanidze method, synthetic values reproduces quit well the distribution function of Gumbel type fitted to the historic data of annual runoff volumes (Figure 2). In figures 3 to 5 we compare the statistics means, standard deviation, skew coefficient, variation coefficient, and the autocorrelation coefficient of one of the 10 daily synthetic series of 100 years generated with the corresponding values of the historically measured data are presented in Figures 3 to 8. 


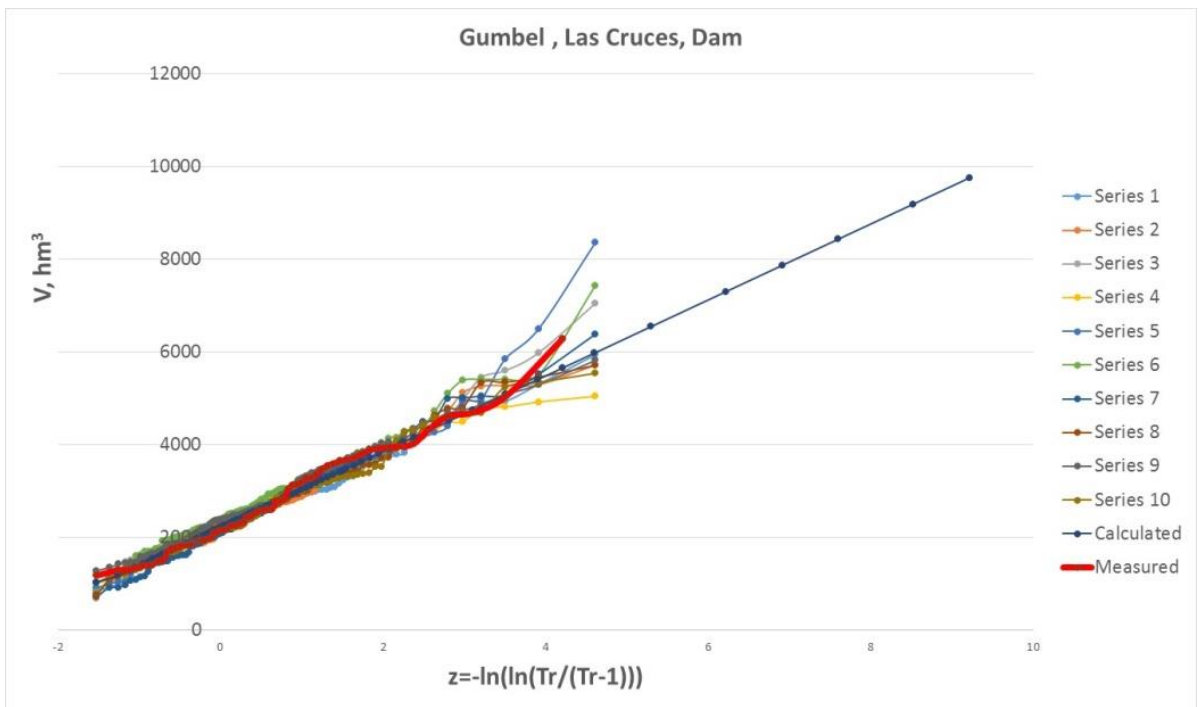

Figure 2: Gumbel distribution function. Measured, calculated and synthetic data. Las Cruces hydroelectric proyect, Nay. México.

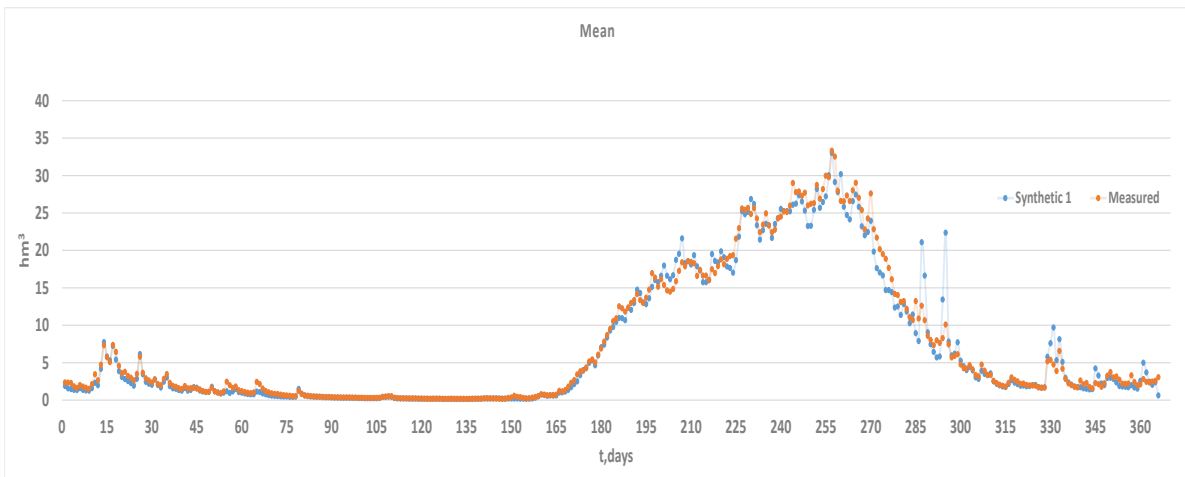

Figure 3: Means of daily measured and synthetic data. Las Cruces hydroelectric proyect, Nay. México.

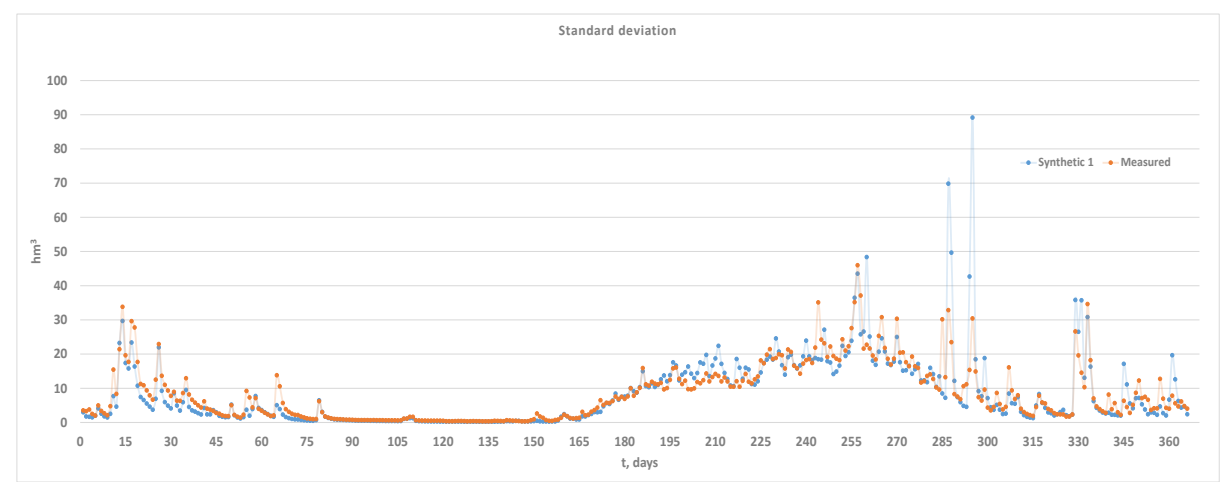

Figure 4: Standard deviation of measured and synthetic data. Las Cruces hydroelectric proyect, Nay. México. 


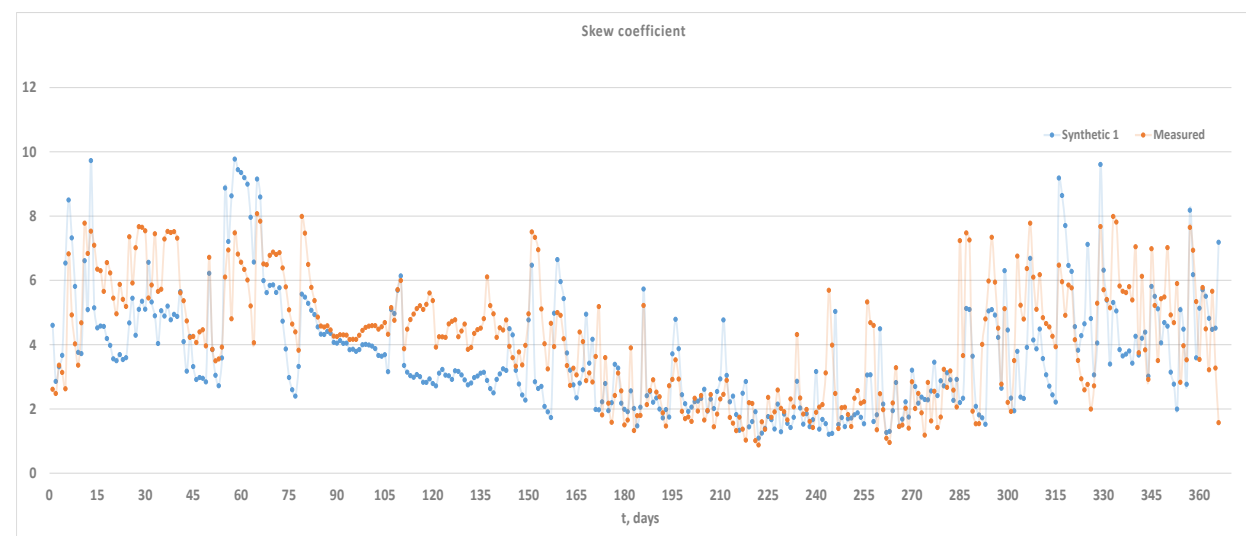

Figure 5: Skew coefficient of measured and synthetic data. Las Cruces hydroelectric proyect, Nay. México.

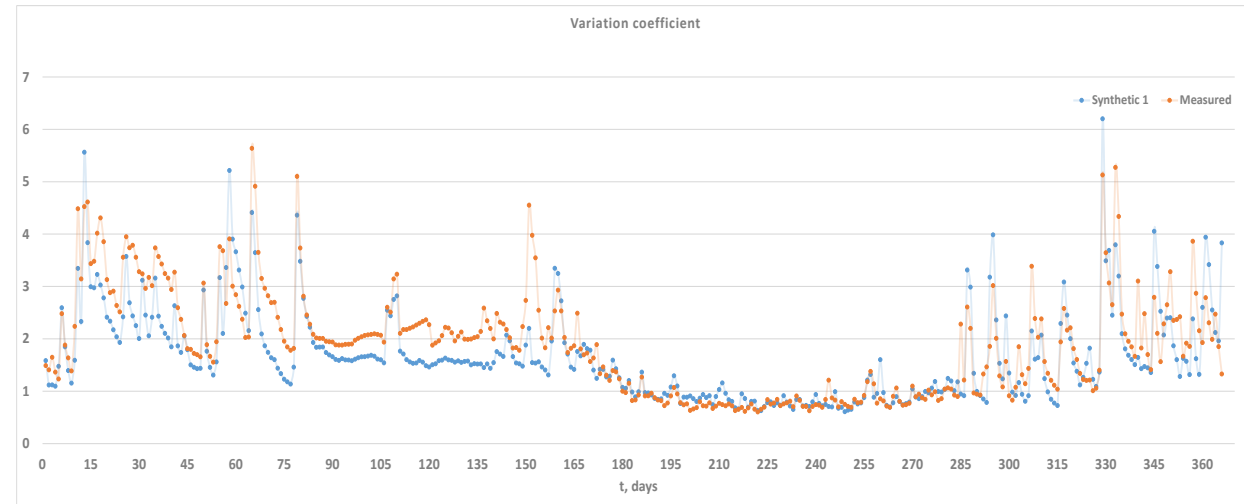

Figure 6: Variation coefficient of daily measured and synthetic data . Las Cruces hydroelectric proyect, Nay. México.

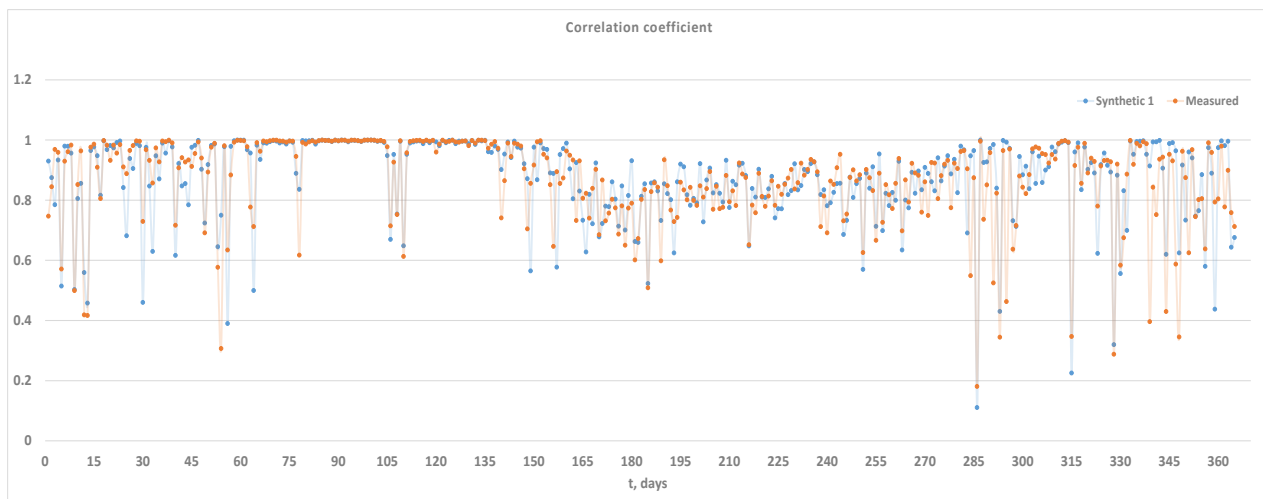

Figure 7: Correlation coefficient of daily measured and synthetic data . Las Cruces hydroelectric proyect, Nay. México.

From the previous figures it is observed that the Svanidze method reproduces the behavior of the daily means, on most days of the year, standard deviations also have a similar behavior; whereas with the coefficient of daily asymmetry it does observe greater fluctuations. The correlations of the data from one day to the next can be reproduced. 
A daily simulation of the dam operation was made, using the policy proposed by the CFE (Table 1) and general design data of the dam (Table 2).

The annual values of the spills and hydroelectric power generated using historical (marked with red color) and the averages obtained by the ten synthetic series are presented in Figures 8 and 9.

Table 1: Operation rule for the intake (maximum daily extraction) CFE $\left(\mathrm{hm}^{3}\right)$

\begin{tabular}{cccccc}
\hline Jan & Feb & Mar & Apr & May & Jun \\
\hline 2.59 & 2.59 & 2.59 & 2.59 & 2.59 & 2.59 \\
\hline Jul & Aug & Sep & Oct & Nov & Dec \\
\hline 13.79 & 15.37 & 15.01 & 9.18 & 2.59 & 2.59 \\
\hline
\end{tabular}

Table 2: Operation data. Las Cruces Dam. CFE

\begin{tabular}{ccccccc}
\hline General data & \multicolumn{3}{c}{ Generation data } \\
\hline Normal Water Level & 238 & $\mathrm{msnm}$ & Outflow level & 84.51 & $\mathrm{msnm}$ \\
Mininum Water Level & 180 & $\mathrm{msnm}$ & Power capacity & 240 & $\mathrm{MW}$ \\
Maximum Water Level & 243 & $\mathrm{msnm}$ & Total Generation & 783 & GWh \\
\hline Design Level & 229 & $\mathrm{msnm}$ & Capacity factor & 0.37 & \\
\hline
\end{tabular}

Figure 8: Spills. Simulation with measured and the average result of the synthetic data. Las Cruces hydroelectric proyect, Nay. México. 


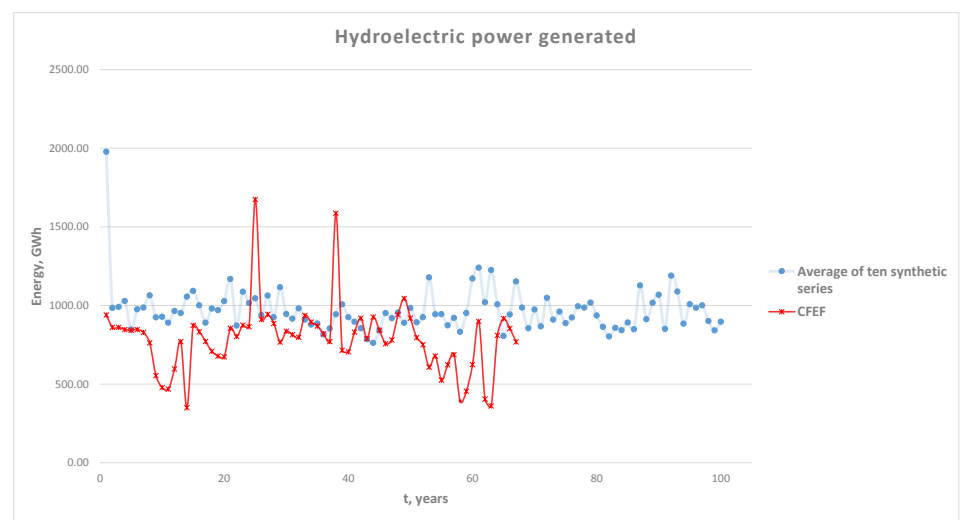

Figure 9: Hydroelectric power generated. Simulation with measured and synthetic data. Las Cruces hydroelectric proyect, Nay. México.

In the case of the annual total outflow in the study, it was considered constant for all years, with values of 2268.21 and 2265.62 in leap years and non-leap years respectively. CFE reported on average a total annual extraction of $2300 \mathrm{hm}^{3}$ (in 68 simulated years).

Figure 8 shows greater annual total spills simulated by CFE than what on average the ten synthetic series report. But the total spills in an average year considering 68 years simulated for the cfe are 382 $\mathrm{hm}^{3}$, while with the synthetic series are $482.69 \mathrm{hm}^{3}$.

Figure 9 shows two years in which the energy generated by the CFE was much higher than the average energy obtained with the synthetic series. The average annual total energy simulated in 68 years by the CFE was $783 \mathrm{GWh}$, while with the ten 100 year synthetic series, the energy was $969.6 \mathrm{Gwh}$.

CFE did not report a deficit, while the average annual deficit with synthetic series was $33.50 \mathrm{hm}^{3}$.

The results of the daily simulation carried out with the operation policy and series also indicated that the number of times that the free surface of water will exceed the maximum permissible level are 5 times per 100 years and below the minimum level would be 14 times, also for every 100 years.

\section{Conclusions}

The Svanidze method was successfully used to generate synthetic series of daily volume data; similar behavior was observed in the statistical parameters as the mean and in the standard deviation of the 10 synthetic series generated.

In the simulations it was observed that on average with the synthetic series, greater generated energy and smaller spills were obtained, but this is attributed to the fact that the number of years of the series generated was greater than that used by the CFE.

It is considered that the results when simulating synthetic records can be improved if a daily operating rule is taken into account based on more details about the assumptions made by the CFE for its daily extractions. 


\section{Referencias}

Domínguez M. R., F. M. (2001). Procedimiento Para Generar Muestras Sintéticas de Series Periódicas Mensuales a trevés del Método de Svanidze Modificado Aplicado a los Datos de las Presas La Angostura y Malpaso. México: Series Instituto de Ingeniería.

M. L. Arganis J., R. D. (2008). Génération d'échantillons synthétiques des volumes mensuels écoulés de deux barrages utilisant la Méthode de Svanidze Modifiée. Hidrolog Sci J53.

M., I. V. (2017). Generación de registros sintéticos diarios usando el método de Svanidze para la Presa las Cruces, Nay. México: Tesina de especialidad, Facultad de Ingeniería, UNAM.

R. Domínguez M., E. C. (2016). Las Cruces, Nay. Revisión del estudio hidrológico para CFE. México: Informe final. 